\title{
GERD in elderly patients: surgical treatment with Nissen-Rossetti laparoscopic technique, outcome
}

\author{
Giovanni Aprea ${ }^{1 *}$, Antonio Ferronetti ${ }^{1}$, Alfonso Canfora ${ }^{1}$, Fabrizio Cardin², Antonio Giugliano ${ }^{1}$, Francesco Guida ${ }^{1}$, \\ Antonio Braun ${ }^{1}$, Melania Battaglini Ciciriello ${ }^{1}$, Federica Tovecci ${ }^{1}$, Giovanni Mastrobuoni ${ }^{1}$, Bruno Amato ${ }^{1}$ \\ From XXV National Congress of the Italian Society of Geriatric Surgery \\ Padova, Italy. 10-11 May 2012
}

\begin{abstract}
Background: The gastro-esophageal reflux disease (GERD) is one of the most frequent disease of the upper gastro-entheric tract. Surgical treatment is reserved to selected patients, affected by severe forms of disease and/or without compliance to medical therapy.

In $95 \%-60 \%$ of the patients submitted to surgical antireflux intervention, a notable improvement of the quality of life is observed.

Functional evaluations performed on pre and post - surgical pHmetric and manometric examination have provided new acquisitions about improvements in the restoration of anatomical and functional integrity of the esophagus-gastric antireflux barrier.

Methods: 45 elderly patients with GERD were recruited in a 27 months period. All patients were subjected to laparoscopic Nissen-Rossetti $360^{\circ}$ fundoplication. The subjects had a pre-surgical evaluation with:

- 24 hours pHmetry,

- esophageal manometry,

The same evaluation was repeated 1 month and 6 months after surgical intervention.

Results: In our series all patients get benefit from surgical treatment, with an improvement of pHmetric and manometric parameters and a regression of complications of GERD such as Barrett's metaplasia. In 8.33\% of patients a PPI therapy was necessary, after the surgical intervention, to control symptoms.

Conclusions: The role of surgery in GERD concerns selected patients. Nissen-Rossetti mini-invasive approach is performed with an acceptable percentage of complications (3\%-10\%). This technique is associated with a good control of GERD symptoms in a short and middle term and with an improvement of functional parameters, such as pHmetric and manometric.
\end{abstract}

\section{Background}

GERD represents the most frequent disease of the upper gastro-enteric tract: the prevalence in elderly patients is $10 \%-20 \%[1,2]$. The incidence is around 5 new cases for 1000 people every year, without differences for sex; besides, the disease more frequently appears in elderly patients [3] and in association with obesity and smoke [4-7].

\footnotetext{
* Correspondence: giovanni.aprea@yahoo.it

'Department of General, Geriatric, Oncologic Surgery and Advanced Technologies, University "Federico II" of Naples, Via Pansini, 5 - 80131 Naples, Italy

Full list of author information is available at the end of the article
}

Patient with evidence of severe esophageal lesions (ulcerations, stenosis or Barrett metaplasia) and incomplete symptomatological resolution or recurrence under medical therapy, patient with long duration symptoms or those of young age in which the symptoms persists, should be considered for surgical intervention [8-12].

In the $90 \%-95 \%$ of the patients submitted to surgical antireflux intervention, the resolution of heartburn and regurgitation with notable improvement of quality of the life is observed [11,12]. The answer of the extra-esophageal symptoms to the surgery varies from $60 \%$ to $80 \%$. In general, $3-10 \%$ of patients shows complications; a lot of

\section{Biomed Central}

(C) 2012 Aprea et al; licensee BioMed Central Ltd. This is an Open Access article distributed under the terms of the Creative Commons Attribution License (http://creativecommons.org/licenses/by/2.0), which permits unrestricted use, distribution, and reproduction in any medium, provided the original work is properly cited. 
complications are minimal and related to surgical interventions, others are more specifically reported to the techniques or to the approach, such as post-operative disphagy (reported in 20\% of the patients) [12].

\section{Methods}

The objective of this longitudinal study is to evaluate the effectiveness of videolaparoscopic $360^{\circ}$ NissenRossetti fundoplication, in the resolution of GERD related symptoms and in the restoration of anatomical and functional integrity of esophagus-gastric antireflux barrier, in elderly patients, who are elegible of mininvasive surgery, due to their comorbidity.

We conducted a prospective study in a period from September 2009 to January 2012, on 45 elderly patients, treated with VLP Nissen-Rossetti fundoplication. Of these, $36(80 \%)$ completed the follow up to six months, while 9 (20\%) have not respected the post-operative protocol, underlining a scarce compliance to undergo invasive examinations. The people that have not completed the first and/or the second post-surgical control have been excluded from the study.

The inclusion criteria for the study were:

1. Patient age $>65$

2. Long-term diagnosis of GERD

3. Refractory or intolerated symptoms with conservative treatment, presence of GERD's atypical symptoms or complications, non-compliance to a long term conservative therapy

4. Absence of other functional esophageal disorders and normal esophageal motility

5. 24 hours pH-metry and/or esophageal manometry suggestive of GERD

6. Comorbidities as cardiovascular disease, diabetes, respiratory disease, etc.

The patients have been preliminarily submitted to a 24 hours pH-metry and to an esophageal manometry; before pHmetric and manometric examinations, patients had to suspend at least for a week the assumption of antisecretive and antiacid drugs, and stop the assumption of prokinetic drugs and medicines that could interfere with the basal tone of the LES (nitrates, calcium-antagonists, aminophylline, beta2-agonists, etc) at least 24 hours before the investigations $[9,13,14]$. The study foresaw a follow up of six months, that consisted in the repetition of 24 hours pH-metry and manometry one month and six months after the surgical intervention.

Among the different parameters evaluated as functional examinations employed in the study, the ones selected to evaluate the effectiveness of antireflux intervention were:

- for the esophageal manometry: relatively to lower esophageal sphincter (LES), the basal LES tone, whose normal value is $>10 \mathrm{mmHgs}$ and the percentage of relaxation, whose normal value is $>85 \%$; relatively to peristalsis, the ampleness of the peristaltic wave, whose normal interval is between 30 and $180 \mathrm{mmHgs}$;

- for the 24 hours pH-metry: the acid refluxes number, the esophageal acid exposure time fraction $(\mathrm{pH}<$ 4 ), whose normal value is inferior to $4 \%$, and finally the correlation between episodes of reflux and symptoms, valued with SAP (Symptom Association Probability), that assumes a meaningful value when it is superior to $95 \%$.

On pre-operative and post-operative pHmetric and manometric parameters we applied $t$-Student test for coupled data, with n-1 degrees of freedom (DoF 12-1 =11) and a $P$ value $<0.05$

\section{Results and discussion}

Among the 36 patients evaluated, 21 of them were male (58.3\%), while 15 female (41.7\%), reflecting a substantial homogeneity in disease distribution in the two sexes (Table 1).

The age range varied between 65 and 76 years, with a 70.83 years middle age. The middle age for men was of 71.57 years; contrarily the average age for women was of 69.79 years (Table 1). Among the 36 patients, 3 of them (8.33\%) were affected by Barrett's metaplasia.

As the results shown in tables 2 and 3, the LES tone middle value at pre-operative manometry was 15.46 mmHgs, with a standard deviation of 13.49; at the first post-surgical control such parameter had a middle value of $25.33 \mathrm{mmHgs}$ (statistically meaningful increase of $63.84 \%$, in comparison to the initial middle value, $\mathrm{P}=$ 0.042 ), with a standard deviation of 1.86; after 6 months from intervention the LES tone middle value was 25.59 mmHgs (statistically meaningful increase of $65.52 \%$ in comparison to the initial value, $\mathrm{P}=0,038$; not statistically meaningful increase of $1.03 \%$ in comparison to middle value after one month, $\mathrm{P}=0.20$ ), with a standard deviation of 1.87 .

About LES relaxation, pre-operative middle value was $107.6 \%$ with a standard deviation of 38.74 ; at the first control the middle value was $85.73 \%$ (statistically meaningful decrease of $20.33 \%, P=0.032$ ), with a standard deviation of 24.5; at the second control the middle value was $82.95 \%$ (statistically meaningful decrease of $22.91 \%$ in comparison to the pre-operative value, $\mathrm{P}=0.029$; not statistically meaningful decrease of $3.24 \%$ in comparison

Table 1 Sex and middle age of sample

\begin{tabular}{lll}
\hline Sex & $\mathbf{N}^{\circ}$ of patients & Middle age \\
\hline $\mathrm{M}$ & 21 & 71.57 \\
\hline $\mathrm{F}$ & 15 & 69.79 \\
\hline Total & 36 & 70.83 \\
\hline
\end{tabular}


Tab.2 Middle values, standard deviations, percentage of variations concerning the parameters evaluated in the study

\begin{tabular}{|c|c|c|c|c|c|c|c|c|}
\hline Parameter & $\begin{array}{l}\text { Pre-surgical } \\
\text { middle value }\end{array}$ & $\begin{array}{l}\text { Pre-surgical } \\
\text { Standard } \\
\text { deviation }\end{array}$ & $\begin{array}{l}\text { One month-post- } \\
\text { surgical middle } \\
\text { value }\end{array}$ & $\begin{array}{l}\text { One month-post- } \\
\text { surgical standard } \\
\text { deviation }\end{array}$ & $\begin{array}{l}\text { Variation } \\
(\%)\end{array}$ & $\begin{array}{l}\text { Six months-post- } \\
\text { surgical middle } \\
\text { value }\end{array}$ & $\begin{array}{c}\text { Six months-post- } \\
\text { surgical standard } \\
\text { deviation }\end{array}$ & Variation (\%) \\
\hline LES tone (mmHgs) & 15.46 & 13.49 & 25.33 & 1.86 & $\begin{array}{c}\uparrow \\
63.84 \%\end{array}$ & 25.59 & 1.87 & $\begin{array}{c}\uparrow \\
65.52 \% \text { and } \\
\uparrow \\
1.03 \% \text { (than } \\
\text { past control) }\end{array}$ \\
\hline LES relaxation (\%) & 107.6 & 38.74 & 85.73 & 24.5 & $20.33 \%$ & 82.95 & 22.35 & $\begin{array}{c}\downarrow \\
22.91 \% \text { and } \\
\downarrow \\
3.24 \% \text { (than } \\
\text { past control) }\end{array}$ \\
\hline $\begin{array}{l}\text { Peristalsis Amplitude } \\
\text { (mmHgs) }\end{array}$ & 91.25 & 33.60 & 73.65 & 17.28 & $19.29 \%$ & 72.61 & 17.51 & $\begin{array}{c}20.43 \% \text { and } \\
\downarrow \\
1.41 \% \text { (than } \\
\text { past control) } \\
\end{array}$ \\
\hline $\mathrm{N}^{\circ}$ of acid refluxes & 149.54 & 65.54 & 88.27 & 33.26 & $40.97 \%$ & 85.27 & 30.96 & $\begin{array}{c}\downarrow \\
42.97 \% \text { and } \\
\downarrow \\
\text { 3.4\% (than past } \\
\text { control) }\end{array}$ \\
\hline $\begin{array}{l}\text { Esophageal acid exposure } \\
\text { fraction of time } \mathrm{pH}<4(\%)\end{array}$ & 10.25 & 5.68 & 3.81 & 2.63 & $\begin{array}{l}\downarrow \\
62.83 \%\end{array}$ & 3.34 & 1.18 & $\begin{array}{c}67.41 \% \text { and } \\
\downarrow \\
\text { and } 12.34 \% \\
\text { (than past } \\
\text { control) } \\
\end{array}$ \\
\hline SAP (\%) & 96.35 & 25.52 & 54.28 & 28.12 & $\begin{array}{l}\downarrow \\
43.66 \%\end{array}$ & 60.44 & 24.45 & $\begin{array}{c}37.27 \% \text { and } \\
\uparrow \\
11.35 \% \text { (than } \\
\text { past control) }\end{array}$ \\
\hline
\end{tabular}


Tab.3 t-Student test for coupled data with $n-1$ degrees of freedom (DoF 12-1 =11) and $P$ value $<0,05$

\begin{tabular}{llll}
\hline -Student & $\begin{array}{l}\text { Pre-surgical value vs one } \\
\text { month-post-surgical values }\end{array}$ & $\begin{array}{l}\text { Pre-surgical value vs six } \\
\text { months-post-surgical values }\end{array}$ & $\begin{array}{l}\text { One month-post-surgical values vs six } \\
\text { months-post-surgical values }\end{array}$ \\
\hline LES tone & $P=0.042$ & $P=0.038$ & $P=0.20$ \\
\hline LES relaxation & $P=0.032$ & $P=0.029$ & $P=0.28$ \\
\hline Peristalsis amplitude & $P=0.041$ & $P=0.038$ & $P=0.37$ \\
\hline $\mathbf{N}^{\circ}$ of acid refluxes & $P=0.026$ & $P=0.015$ & $P=0.52$ \\
\hline $\begin{array}{l}\text { Esophageal acid exposure } \\
\text { fraction of time }\end{array}$ & $P=0.019$ & $P=0.004$ & $P=0.46$ \\
\hline SAP & $P=0.011$ & $P=0.01$ & $P=0.13$ \\
\hline
\end{tabular}

to the middle value of first control, $\mathrm{P}=0.28$ ), while the standard deviation was 22.35 .

Considering peristalsis amplitude, pre-surgical middle value was $91.25 \mathrm{mmHgs}$ with a standard deviation of 33,60; at the first post-operative control such middle value resulted $73.65 \mathrm{mmHgs}$ (statistically meaningful decrease of $19.29 \%, P=0.041$ ), with a standard deviation of 17.28; at the second control the middle value for such parameter was $72.61 \mathrm{mmHgs}$ (statistically meaningful decrease of $20.43 \%$ in comparison to the initial value, $\mathrm{P}=0.038$; not statistically meaningful decrease of $1.41 \%$ in comparison to the preceding examination, $\mathrm{P}=$ 0.37 ), with a standard deviation of 17.51 .

Concerning pHmetric parameters, the pre-operative middle number of acid refluxes in the sample was 149.54, with a standard deviation of 65.54; one month after surgical intervention the middle number of acid refluxes was 88.27 (statistically meaningful decrease of $40.97 \%, \mathrm{P}=0.026$ ), with a standard deviation of 33.26 ; after six months the middle number of acid refluxes was 85.27 (statistically meaningful decrease of $42.97 \%$ in comparison to the pre-surgical values, $\mathrm{P}=0.015$; not statistically meaningful decrease of $3,4 \%$ in comparison to the middle value after one month from the intervention, $\mathrm{P}=0.52$ ) with a standard deviation of 30.96 .

The pre-operative middle value of esophageal acid exposure fraction of time was $10.25 \%$, with a standard deviation of 5.68; one month after surgical intervention the middle value was $3.81 \%$ (statistically meaningful decrease of $62.83 \%, \mathrm{P}=0.019$ ), with a standard deviation of 2.63; after six months, instead, the middle value resulted $3.34 \%$ (statistically meaningful decrease of $67.41 \%$ in comparison to initial middle value, $\mathrm{P}=0,004$; not statistically meaningful decrease of $12.34 \%$ in comparison to the middle value after one month from the intervention, $\mathrm{P}=0.46$ ) with a standard deviation of 1.18.

Relatively to pre-operative middle value of SAP, it resulted $96.35 \%$, with a standard deviation of 25.52 ; at the first control the middle value of SAP was $54.28 \%$ (statistically meaningful decrease of $43.66 \%, \mathrm{P}=0.011$ ), with a standard deviation of 28.12, at the second control the middle value was $60.44 \%$ (statistically meaningful decrease of $37.27 \%$ in comparison to the initial middle value, $\mathrm{P}=0.01$; not statistically meaningful increase of $11.35 \%$ in comparison to the measured value after one month from intervention, $\mathrm{P}=0.13$ ) with a standard deviation of 24.45 .

\section{Conclusions}

As already affirmed in other studies, Nissen-Rossetti fundoplication seems to offer indeed a good control of GERD in a short and middle term evaluation, better than other antireflux surgical techniques.

This prospective study has been conducted with the purpose to appraise the real effectiveness of surgical procedure in functional integrity restoration of esophagus-gastric junction, in elderly patients with refractive symptoms to medical therapy. The results of this study show that:

1. In $92,67 \%$ of patients submitted to Nissen-Rossetti fundoplication, $\mathrm{pH}$-metric parameters vary with a return within physiological range (reduction of: acid refluxes number, fraction of time of acid esophageal exposure and SAP);

2. The LES basal tone is improved in comparison to the pre-operative period, in all patients.

3. The LES relaxation is decreased, however in the normal range, in comparison to the pre-surgical values, in all patients.

4. In $83.34 \%$ of patients, peristalsis is reduced in the post-surgical period, preserving values in normal range.

5. In $100 \%$ of patients affected by Barrett's metaplasia (3 patients), the surgical intervention caused the regression of metaplasia.

6. In $8.33 \%$ of patients a PPI therapy was necessary, after the surgical intervention, to control gastric acid secretion and reflux episodes.

From our study, laparoscopic surgical intervention, performed with Nissen-Rossetti technique, gives a statistically meaningful improvement, considering functional parameters, such as pHmetric and manometric. There are not appreciable differences, instead, between parameters evaluated between, one month and six months after intervention, probably because anatomo-functional 
improvements of the gastro-esophageal tract are appreciable since the immediate post-operative period. Staying our evidences to confirm, we have programmed the prosecution of our experimental study for the next two years, with the intent to reach a sample of subjects such to be able to get more meaningful conclusions concerning the functional results of surgical intervention.

\section{List of abbreviations}

GERD: Gastro-esophageal reflux disease; LES: lower esophageal sphincter; VLP: videolaparoscopy.

\section{Acknowledgements}

This article has been published as part of BMC Surgery Volume 12 Supplement 1, 2012: Selected articles from the XXV National Congress of the Italian Society of Geriatric Surgery. The full contents of the supplement are available online at http://www.biomedcentral.com/bmcsurg/supplements/12/s1.

\section{Author details}

'Department of General, Geriatric, Oncologic Surgery and Advanced Technologies, University "Federico II" of Naples, Via Pansini, 5 - 80131 Naples, Italy. ${ }^{2}$ Department of Surgical and Gastroenterological Sciences, Padova University Hospital, Italy, Via Giustiniani n.2, 35126 Padova, Italy.

\section{Authors' contributions}

GA, BA: conception and design, interpretation of data, given final approval of the version to be published, $A G, A C, A F, A B, M B C, F T, G M, F G$ : acquisition of data, drafting the manuscript, given final approval of the version to be published, FC: acquisition of data, drafting the manuscript, given final approval of the version to be published.

\section{Competing interests}

The authors declare that they have no competing interests.

Published: 15 November 2012

\section{References}

1. Fass R: Epidemiology and patophysiology of symptomatic gastroesophageal reflux disease. Am J Gastroenterol 2003, 98(3 Suppl):S2-7.

2. Dent J, El-Serag HB, Wallander M-A, Johansson S: Epidemiology of gastrooesophageal reflux disease: a systematic review. Gut 2005, 54:710-717.

3. Johnson DA, Fennerty MB: Heartburn severity underestimates erosive esophagitis severity in elderly patients with gastroesophageal reflux disease. Gastroenterology 2004, 126:660-64.

4. Lagergren J: Influence of obesity on the risk of esophageal disorders. Nat Rev Gastroenterol Hepatol 2011, 8(6):340-7.

5. Moayyedi P, Talley NJ: Gastro-oesophageal reflux disease. The Lancet 2006, 367(9528):2086-2100.

6. Chait MM: Gastroesophageal reflux disease; important considerations for the older patients. World J Gastrointest Endosc 2010, 2:388-396.

7. de Vries DR, van Herwaarden MA, Smout AJ, Samsom M: Gastroesophageal pressure gradients in gastroesophageal reflux disease: relations with hiatal hernia, body mass index, and esophageal acid exposure. Am J Gastroenterol 2008, 103(6):1349-54.

8. Malfertheiner $P$, Hallerback B: Clinical manifestations and complications of gastroesophageal reflux disease (GERD). International Journal of Clinical Practice 2005, 59(3):346-355.

9. De Vault KR, Castell DO: American College of Gastroenterology. Updated Guidelines for the diagnosis and treatment of gastroesophageal reflux disease. Am J Gastroenterol 2005, 100:190-200.

10. Lyn Patrick ND: Gastroesophageal Reflux Disease (GERD): A Review of Conventional and Alternative Treatments. Altern Med Rev 2011, 16(2):116-33.

11. Ip $S$, Bonis $P$, Tatsioni $A$, et al: Comparative effectiveness of management strategies for gastroesophageal reflux disease. Comparative Effectiveness Reviews, No 1. Rockville, MD: Agency for Healthcare Research and Quality 2005, PMID: 21348043 [PubMed].
12. Varin $O$, Velstra B, De Sutter $S$, Ceelen W: Total vs partial fundoplication in the treatment of gastroesophageal reflux disease: a meta-analysis. Arch Surg 2009, 144(3):273-8.

13. Zerbib F, Roman S, Ropert A, des Varannes SB, Pouderoux P, Chaput U, Mion F, Vérin E, Galmiche JP, Sifrim D: Esophageal pH-impedance monitoring and symptom analysis in GERD: a study in patients off and on therapy. Am J Gastroenterol 2006, 101(9):1956-63.

14. Sharma N, Agrawal A, Freeman J, et al: An analysis of persistent symptoms in acid-suppressed patients undergoing impedance-pH monitoring. Clin Gastroenterol Hepatol 2008, 6:521-524.

doi:10.1186/1471-2482-12-S1-S4

Cite this article as: Aprea et al:: GERD in elderly patients: surgical treatment with Nissen-Rossetti laparoscopic technique, outcome. BMC Surgery 2012 12(Suppl 1):S4.

\section{Submit your next manuscript to BioMed Central and take full advantage of:}

- Convenient online submission

- Thorough peer review

- No space constraints or color figure charges

- Immediate publication on acceptance

- Inclusion in PubMed, CAS, Scopus and Google Scholar

- Research which is freely available for redistribution
C Biomed Central 